\title{
KARTAGENER'S SYNDROME
}

Swati M. Gadappa ${ }^{1}$, Anamika Bakliwal ${ }^{2}$

\section{HOW TO CITE THIS ARTICLE:}

Swati M. Gadappa, Anamika Bakliwal. "Kartagener's Syndrome". Journal of Evolution of Medical and Dental Sciences 2014; Vol. 3, Issue 60, November 10; Page: 13458-13461, DOI: 10.14260/jemds/2014/3793

ABSTRACT: BACKGROUND: Kartagener syndrome (a clinical variant of primary ciliary dyskinesia) is an autosomal recessive disease characterized by the triad of chronic sinusitis, bronchiectasis and situs inversus with dextrocardia. CASE CHARACTERISTICS: A 11-year-old boy presenting with chronic cough with expectoration requiring frequent nebulisations. OUTCOME: Early diagnosis of this rare congenital autosomal recessive disorder in early life is important in the overall prognosis of the syndrome, as many of the complications can be prevented if timely management is instituted, as was done in this in this case.

KEYWORDS: Kartagener's syndrome, sinusitis, situs inversus, Bronchiectasis, primary ciliary dyskinesia.

INTRODUCTION: Siewert first described the combination of situs inversus, chronic sinusitis, and bronchiectasis $^{1}$ in 1904 . However, Manes Kartagener ${ }^{2}$ first recognized this clinical triad as a distinct congenital syndrome in 1933. Kartagener's syndrome (KS) is inherited via an autosomal recessive pattern. Its incidence is about 1 in 30, 000 live births. Male patients with this syndrome are almost invariably infertile because of immotile spermatozoa. It is characterized by ultra-structural abnormalities in the cilia of respiratory tract and tail of spermatozoa. This leads to chronic recurrent sino-pulmonary infection, impaired tracheobronchial clearance, situs inversus in about $50 \%$ of cases, and living but immotile spermatozoa of normal morphology.,3 Kartagener syndrome is included as a subgroup or part of the primary ciliary dyskinesia. We report a 11year old boy with chronic productive cough on recurrent nebulisations.

CASE REPORT: 11year old boy $5^{\text {th }}$ issue of non-consanguinous marriage was admitted with paroxysmal productive non-spasmodic cough, coryza and mild fever since 8days. On enquiry, he had recurrent coryza and mucopurulent expectoration, associated with episodes of fever since 1year of age. He has been on and off on nebulisations and MDI with occasional steroids and antibiotics. Paternal uncle is a known case of bronchial asthma. Elder siblings are all females with no respiratory complaints. Birth history- normal vaginal delivery at full term. Admitted on day5 for respiratory distress and fever. Was found to have Dextrocardia. Child did not require ventilator support. Further was lost to follow-up.

On examination, child is growing well. Developmentally normal for age. He was not tachypneic. Had frequent coughing. He was febrile, conscious, and oriented. No pallor and no icterus. Clubbing grade 1 was present. JVP- Normal. The apex beat was in the right fifth intercostal space in midclavicular line with area of cardiac dullness on the right side. The liver was situated on the left side, with tympanic stomach resonance detected on the right side. Respiratory system examination revealed tenderness over paranasal sinuses and bilateral diffuse ronchi with coarse crepitations over bilateral infrascapular, infra-axillary, and lower mammary regions; more on the right side. 
His investigations revealed $\mathrm{Hb}$ of $11.5 \mathrm{~g} \%$ with leucocytosis [18400/cmm with $90 \%$ neutrophils].CRP-13mg/L. ASO Titre $400 \mathrm{IU} / \mathrm{ml}$. Sputum for acid fast bacilli did not reveal the tuberculosis bacilii. Gram stain of the sputum revealed gram positive cocci in pairs and gram negative bacilli. Sputum culture was sterile. Pulmonary function tests revealed mild obstructive type of ventilatory defect. X-ray paranasal sinus showed bilateral underpneumatized frontal sinuses and maxillary sinusitis. X-ray chest, PA view, revealed right-sided heart and inhomogeneous infiltrates in right lower zone [Figure 1]. On HRCT thorax, there was dextrocardia with Situs inversus, consolidation involving right medial segment of medial lobe and lower lobe on the right side, associated with bronchiectatic changes. [Figure 2,4] Also PNS CT showed hypoplastic frontal and sphenoid sinus with maxillary sinusitis [Figure 3]. 2D Echo showed dextrocardia with situs inversus, no structural heart disease.

Figure 1: X-ray chest, PA view, showing dextrocardia and inhomogeneous infiltrate at both the lower zones in paracardiac region $\mathrm{Rt}>\mathrm{Lt}$.

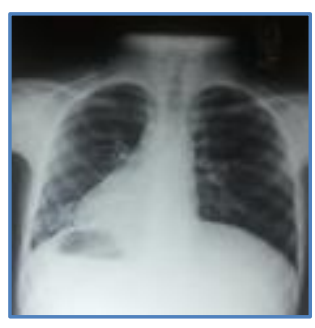

\section{Fig. 1}

Figure 2: HRCT showing dextrocardia with Situs inversus.

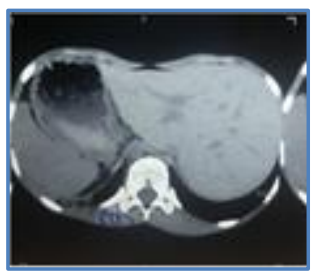

\section{Fig. 2}

Figure 3: CT PNS showing hypoplastic frontal sinuses and maxillary sinusitis.

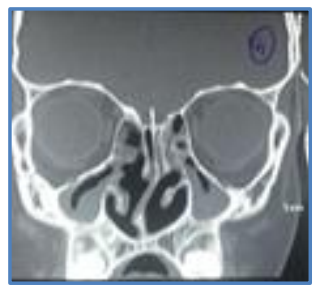

\section{Fig. 3}




\section{CASE REPORT}

Figure 4: HRCT Thorax showing early bronchiectatic changes in right lower lobe of lung.

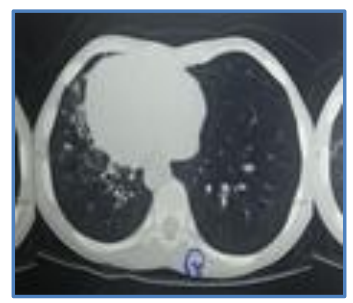

Fig. 4

DISCUSSION: Disorders of ciliary motility may be congenital or acquired. Congenital disorders are labeled as Primary ciliary dyskinesia [PCD]. Nearly 50\% of PCD patients have situs inversus. Such cases of PCD with situs inversus are known as Kartagener's syndrome. ${ }^{5}$ The estimated prevalence of PCD is about 1 in 30, 000, 6 though it may range from 1 in 12,500 to 1 in 50, 000.7

The lower respiratory tract contains ciliated epithelium from the trachea to the respiratory bronchioles. Each ciliated cell gives rise to approximately 200 cilia that vary in length from 5 to $6 \mu \mathrm{m}$ and decrease in size as the airway becomes smaller. Patients with primary ciliary dyskinesia exhibit a wide range of defects in ciliary ultrastructure and motility, which ultimately impairs ciliary beating and mucociliary clearance. The most common defect, first described by Afzelius, is a reduction in the number of dynein arms, which decreases the ciliary beat frequency. Further, it is also observed that none of the ciliary defects observed in ICS are specific.

They may all occur as secondary lesions or sporadically as varieties in otherwise healthy subjects. ${ }^{8}$ We therefore conclude with the remark that ICS should be suspected on clinical grounds in individuals presenting with chronic cough, rhinorrhea, sinusitis, otitis media, obstructive lung disease, etc., along with male sterility and with or without situs inversus.

The diagnostic criteria recommended for this syndrome are history of chronic bronchial infection and rhinitis from early childhood, combined with one or more of following features: (a) situs inversus or dextrocardia in a patient or a sibling, (b) living but immotile spermatozoa, (c) tracheobronchial clearance, which is absent or nearly so. ${ }^{9}$ Our patient had most of the features; however, due to age, immotile spermatozoa could not be demonstrated. Occasionally, Kartagener's syndrome may be associated with reversible airflow obstruction which was seen in our case.

Treatment of this rare congenital disorder includes antibiotics, intravenous or oral, intermittent or continuous, and are used to treat upper and lower airway infections. Hemophilus influenzae and Staphylococcus aureus are the most common organisms. Long-term low-dose prophylactic antibiotics may be necessary in children. Anecdotal treatment regimes for Obstructive lung disease/bronchiectasis include inhaled bronchodilators, mucolytics, and chest physiotherapy. We treated our patient with IV Ceftriaxone followed by oral Linezolid for treatment of right lower zone pneumonia. Later the child was discharged on intermittent antibiotic therapy with inhaled bronchodilator and oral mucolytic therapy. Chest physiotherapy was started.

Vaccination against Influenza and Pneumococcal vaccination must be encouraged in children with PCD. Surgical care involves tympanostomy tubes that will reduce recurrent infections and conductive hearing loss. On follow-up, our patient has reduced incidence of respiratory infections and is growing well. 
Late diagnosis with established bronchiectasis worsens the overall the prognosis, even with the best of treatment modalities. Hence a high degree of suspicion about Kartagener's Syndrome is required in children with chronic productive cough.

\section{REFERENCES:}

1. Seiwert AK. Ueber einen Fall von Bronchiektasie bei einem Patienten mit situs inversus viscerum. Berlin Klin Wschr. 1904; 41: 139.

2. Kartagener M. Pathogenes der Bronchiektasien Mitteilung: Bronchiektasien bei situs viscerum inversus. Beitr Klin Tuberk. 1933; 83: 489.

3. Seaton D. Bronchiectasis. In: Seaton A, Seaton D, Lietch AG, editors. Crofton and Douglas's respiratory diseases. Oxford: Blackwell Science; 2004. pp. 794-828.

4. Eliason R, Mossberg B, Camner P, Afzelius BA. The immotile cilia syndrome: A congenital ciliary abnormality as an etiologic factor in chronic airway infection and male sterility. $\mathrm{N}$ Engl J Med. 1977; 297: 1-6. [PubMed].

5. Olbrich H, Häffner K, Kispert A, Völkel A, Volz A, Sasmaz G, et al. Mutations in DNAH5 cause primary ciliary dyskinesia and randomization of left-right asymmetry. Nat Genet. 2002; 30: 143-4. [PubMed].

6. Seaton D. Bronchiectasis. In: Seaton A, Seaton D, Leitch AG, editors. Crofton and Douglas's respiratory diseases. 5th ed. Oxford: Blackwell Science; 2004. pp. 794-828.

7. Barthwal MS. Kartagener's syndrome in a fertile male - An uncommon variant. Lung India. 2006; 23: 123-5.

8. Fischer L, Burri PH, Bauer W, Kraemer R, Sauter K. How useful is the ultra-structural study of the cilia of the respiratory tract in the diagnosis of the immotile cilia syndrome? Schweiz Med Wochenschr. 1984; 114: 610-9. [PubMed].

9. Afzelius BA, Mossberg B. Immotile cilia. Thorax. 1980; 35:401-4. [PMC free article] [PubMed].

\section{AUTHORS:}

1. Swati M. Gadappa

2. Anamika Bakliwal

\section{PARTICULARS OF CONTRIBUTORS:}

1. Assistant Professor, Department of Paediatrics, Bharati Vidyapeeth Medical College, Pune.

2. Post Graduate Resident, Department of Paediatrics, Bharati Vidyapeeth Medical College, Pune.

\section{NAME ADDRESS EMAIL ID OF THE CORRESPONDING AUTHOR: \\ Dr. Swati Gadappa, 601/B3, Runwal Seagull Township, Handewadi Road, Hadapsar, Pune-411028. \\ Email: swatigadappa@yahoo.co.in}

Date of Submission: 04/11/2014. Date of Peer Review: 05/11/2014. Date of Acceptance: 06/11/2014. Date of Publishing: 10/11/2014. 